\title{
RISK ANALYSIS FOR CODE CALIBRATION
}

\author{
Andrzej S. Nowak \\ Department of Civil Engineering, University of Michigan, Ann Arbor, MI 48109 (U.S.A.)
}

(Received October 27, 1982: accepted April 5, 1983)

Key words: Safety index, building code, load combinations, load factors, performance factors, safety factors.

\section{ABSTRACT}

A procedure has been developed to calibrate safety indices for various types of structures.

The load model is based on normal approximations of non-normal distributions at the design point. For time varying loads, the basic time intervals are considered, with probabilities of occurrence in each interval and conditional distributions of intensity.
Load and resistance factor format and allowable stress design are considered. Computations were carried out for the National Building Code of Canada.

Safety indices are presented in charts and tables. The results can be used to determine optimum values of resistance factors and/or safety factors.

\section{INTRODUCTION}

The development of a building code involves the optimization of load and resistance factors. There is a need for an efficient numerical procedure to compare safety of structures corresponding to different code requirements (load and resistance factors). Nowak and Lind [1] developed a procedure, based on Rackwitz and Fiessler's model [2], to optimize resistance factors. Recently, also based on that model, the computer program was developed and safety indices were calculated for various cases of beams and columns. The present paper describes the procedures and results of these computations.

Five load components are considered: dead load, live load, snow, wind and earthquake. Live load is considered as a sum of sustained live load and transient live load. The load models are based on the presently available data.

Safety indices were calculated for the beams and columns designed according to the $\mathrm{Na}$ tional Building Code of Canada [3], for various load cases. The results are presented in the form of charts and tables and can be used in selection of resistance factors or safety factors, as demonstrated. 


\section{SAFETY INDEX}

The procedure to calculate safety indices is described by Nowak and Lind [1]. A brief summary is given here.

The limit state equation for the considered design cases is

$Z=R-(D+L S+L T+S+W+E)$

where $R=$ resistance, or load carrying capacity of the structure, $D=$ dead load effect, $L S=$ sustained live load effect, $L T=$ transient live load effect, $S=$ snow effect, $W=$ wind effect, and $E=$ earthquake effect. $Z \geqslant 0$ corresponds to safe realizations, while $Z<0$ corresponds to failure. Probability of failure. $P_{F}$. is

$P_{\mathrm{F}}=\operatorname{Prob}(Z<0)$.

Safety index, $\beta$, is defined as

$\beta=-\Phi^{-1}\left(P_{\mathrm{F}}\right)$

where $\Phi^{-1}()=$ inverse of the standard normal distribution function.

If all the variables in eqn. 1 are independent and normally distributed, then $Z$ is also a normal random variable with the mean $\bar{Z}$ and standard deviation $\sigma_{\mathrm{Z}}$ given by

$\bar{Z}=\bar{R}-(\bar{D}+\overline{L S}+\overline{L T}+\bar{S}+\bar{W}+\bar{E})$,

$\sigma_{Z}=\left(\sigma_{R}^{2}+\sigma_{D}^{2}+\sigma_{L S}^{2}+\sigma_{L T}^{3}+\sigma_{S}^{2}+\sigma_{W}^{2}+\sigma_{E}^{2}\right)^{1 / 2}$.

where

$\bar{R}, \ldots, \bar{E}, \sigma_{R}^{2}, \ldots, \sigma_{E}^{2}=$ means and variances of $R, \ldots, E$.

The probability of failure is

$P_{\mathrm{F}}=\Phi\left(-\bar{Z} / \sigma_{Z}\right)$

and hence in this case, from eqn. 3 ,

$\beta=\bar{Z} / \sigma_{Z}$

If the variables in eqn. 1 are not normally distributed, then $\beta$ can be calculated using Rackwitz and Fiessler's iterative procedure [2]. The method is based on normal ap- proximations of non-normal distributions. The approximating normal distribution is selected so, that its cumulative distribution function (CDF) and its probability density function (PDF) are equal to the CDF and PDF of the original distribution at the so called "design point". Design point, denoted by $R^{*}, \ldots E^{*}$. are values for $R \ldots$. E such that

$$
\begin{aligned}
& R^{*}-\left(D^{*}+L S^{*}+L T^{*}+S^{*}\right. \\
& \left.\quad+W^{*}+E^{*}\right)=0 .
\end{aligned}
$$

Initial values of $R^{*}, \ldots E^{*}$. satisfying eqn. 8. are guessed first. The mean. $\bar{X}^{\prime}$ and the standard deviation, $\sigma_{X}$. of the approximating normal distribution are calculated form the following formulas;

$$
\begin{aligned}
& \boldsymbol{\sigma}_{X^{\prime}}=\varphi\left\{\Phi^{-1}\left[F_{X}\left(X^{*}\right)\right]\right\} / f_{X}\left(X^{*}\right) \\
& \bar{X}=X^{*}-\sigma_{X}, \Phi^{-1}\left[F_{X}\left(X^{*}\right)\right]
\end{aligned}
$$

where $X=R, \ldots, E, \varphi=$ PDF of the standard normal random variable, and

$f_{X}()=$ PDF of $X$.

For those approximated distributions the mean and standard deviation of $Z^{\prime}$ can be calculated using eqns. 4 and 5 .

$$
\begin{aligned}
\bar{Z}^{\prime}= & \bar{R}^{\prime}-\left(\overline{D^{\prime}}+\overline{L S^{\prime}}+\overline{L T^{\prime}}+\overline{S^{\prime}}\right. \\
& \left.+\bar{W}^{\prime}+\bar{E}^{\prime}\right) \\
\sigma_{Z^{\prime}}= & \left(\sigma_{R^{\prime}}^{2}+\sigma_{D^{\prime}}^{2}+\sigma_{L S^{\prime}}^{2}+\sigma_{L T^{\prime}}^{2}+\sigma_{S^{\prime}}^{2}\right. \\
& \left.+\sigma_{W^{\prime}}^{2}+\sigma_{E^{\prime}}^{2}\right)^{1 / 2}
\end{aligned}
$$

and the safety index is

$\beta=\bar{Z}^{\prime} / \boldsymbol{\sigma}_{Z^{\prime}}$.

The iteration loop is completed after the new design points are found from the following formula,

$X^{*}=\bar{X}^{\prime} \pm \beta \sigma_{X^{\prime}}^{2} / \sigma_{Z^{\prime}}$

where $X=R, \ldots, E$. A minus sign is used for $R$ (or negative loads). Then new approximating normal distributions are calculated using eqns. 9 and 10 , and a new $\beta$ is calculated using eqn. 13. The calculations are continued 
until $\beta$ does not differ in the consecutive iterations (within the required accuracy).

The presented procedure allows for the calculation of $\beta$ for time-invariant loads and resistance. However, earthquake, wind, snow and live load are time-variant. Therefore the model is modified to account for this variation.

For each load component a basic time interval, $\tau$, is determined. It is assumed that load magnitude can be considered constant during this time period.

The occurrence or non-occurrence of the load in each time interval corresponds to repeated independent trials with probability $p$ of occurrence. Given that the load occurs the distribution of its amplitude is $F_{\text {int }}(x)$ and the corresponding PDF is $f_{\mathrm{int}}(x)$.

For $n$ basic time intervals the cumulative distribution function, $F(x)$, and the probability density function, $f(x)$, for each load component can be written as

$$
\begin{aligned}
& F(x)=\left\{1-p\left[1-F_{\mathrm{int}}(x)\right]\right\}^{n} \\
& f(x)=n p f_{\mathrm{int}}(x)[F(x)]^{(n-1) / n}
\end{aligned}
$$

The combined effect of the considered load components is calculated as follows. The loads are arranged by increasing $\tau$ 's: $E, W, L T, S$, $L S, D$. . Dead load and resistance are assumed to be time invariant. $E$ is combined with $W$ first. The basic time interval for $E$ is $\tau_{E}$. The CDF and PDF of $E$ in the time interval $\tau_{W}$ (basic time interval for $W$ ) is calculated using eqns. 15 and 16 with $n=\tau_{W} / \tau_{E}$. The distributions of $E$ and $W$, both in time interval $\lambda_{W}$, are approximated by normal distributions at $E^{*}$ and $W^{*}$, respectively. The parameters of the approximating normal distributions are calculated using eqns. 9 and 10. The joint distribution of $E+W$ in time interval $\lambda_{W}$ is then normal, with the mean and variance equal to the sum of means and variances of both components.

The joint distribution of $E$ and $W, E+W$, is combined with $L T$. The value of the CDF and PDF for $(E+W)$ is calculated at $\left(E^{*}+\right.$ $W^{*}$ ), in time interval $\tau_{L T}$ (basic time interval for $L T$ ). It is approximated by a normal distribution at that point, and a normal distribution approximating $L T$ at $L T^{*}$ is added.

Then the joint distribution of $(E+W+$ $L T+S$ ) is calculated, $L S$ is added, then $D$, finally the normal approximation is found for $Z$, as given by eqn. 1 (at the design point). The safety index is calculated from eqn. 13.

New values for $R^{*}$ and $D^{*}$ are determined by using eqn. 14 , and $L S^{*}$ becomes

$$
\begin{aligned}
L S^{*}= & \overline{L S^{\prime}}+\sigma_{L s^{\prime}}^{2}\left[(L S+\ldots+E)^{*}\right. \\
& -\left(\overline{\left.L S+\ldots+E)^{\prime}\right] / \sigma_{(I S+\ldots+E)^{\prime}}^{2}}\right.
\end{aligned}
$$

where $\overline{(L S+\ldots+E)^{\prime}}$ and $\sigma_{(L S+\ldots+E)^{\prime}}^{2}$ are the mean and variance of the approximating normal distribution for the joint distribution of $(L S+\ldots+E)$, at the previous design point. and $(L S+\ldots+E)^{*}$ is the new design point. calculated from eqn. 14 (by replacing $X$ with $(L S+\ldots+E)$. The new values for $S^{*}, L T^{*}$. $W^{*}$ and $E^{*}$ are calculated similarly.

\section{RESISTANCE AND LOAD COMPONENTS}

Each load component is fully determined by the parameters $p$ and $n$ and the CDF of intensity, $F_{\mathrm{int}}(\quad)$. The models of load components and resistance are presented below. The nominal values of loads are those specified by the National Building Code of Canada [3].

Resistance It is assumed that the resistance is time invariant, with $n=1$, and $p=1$.

The CDF of resistance, $F_{\mathrm{R}}(x)$, is taken as lognormal. The lognormal $F_{\mathrm{R}}(x)$ can be calculated using a standard normal distribution function as follows, see [4].

$F_{\mathrm{R}}(x)=\Phi\left(\ln (x / \check{R}) / \sigma_{\ln R}\right)$

where $\check{R}=$ median of $R$.

The median, $\check{R}$, and $\sigma_{\text {in } R}$ can be expressed in terms of the mean resistance, $\bar{R}$, and coefficient of variation of resistance, $V_{R}$ :

$$
\check{R}=\bar{R} \exp \left(-\frac{1}{2} \sigma_{\ln R}^{2}\right), \text { and }
$$


$\sigma_{\ln R}^{2}=\ln \left(V_{R}^{2}+1\right)$

Also the density function of resistance can be expressed in terms of the standard normal density function, $\varphi$ :

$f_{R}(x)=\left(1 / x \sigma_{\ln R}\right) \varphi\left(\ln (x / \check{R}) / \sigma_{\ln R}\right)$

Dead load is considered as time invariant. with $n=1$ and $p=1$. The CDF is assumed to be a normal distribution. The ratio of meanto-nominal is taken as $\lambda_{D}=1.0$ and the coefficient of variation as $V_{D}=10 \%$, including analysis factor.

Live load $L$ is considered as a sum of two components, sustained live load, $L S$, and transient live load, $L T$. $L S$ includes the weight of furniture and removable equipment as well as weight of persons usually in the building. $L T$ includes the weight of items and persons in the building only occasionally, for example, people gathering for a special meeting, or weight of furniture stored in an office during remodelling, etc.

The live load model is derived from the results of statistical studies described by Allen [5] and by Ellingwood et al. [6].

Sustained live load It is assumed that changes of $L S$ occur every 5 years, so $n=10$ for 50 year lifetime, with $p=1.0$ ( $L S$ is always present). The CDF of intensity, $F_{L S}$, is a gamma distribution,

$F_{L S}(x)=\Gamma(k, \lambda x) / \Gamma(k)$

where $\Gamma(k, \lambda x)=\int_{0}^{\lambda x} \mathrm{e}^{-u} u^{k-1} \mathrm{~d} u$, and $\Gamma(k)=$ $\int_{0}^{\infty} \mathrm{e}^{-u} u^{k-1} \mathrm{~d} u, k$ and $\lambda$ are constants. Consequently the density function of LS is

$f_{L S}(x)=\frac{\lambda}{L}\left(\frac{\lambda x}{L}\right)^{k-1} \mathrm{e}^{\lambda x /} /(k)$

where $L=$ nominal live load as specified in the National Building Code of Canada [3]. The parameters $k$ and $\lambda$ depend on the parameters of the sustained live load distribution.

The statistical studies of live load provide arbitrary-point-in-time values of $L S$. These values correspond to realizations of intensity of $L S$. The ratios of mean-to-nominal and the coefficients of variation of $L S$ are given in Table 1.

For the gamma distribution the mean, $\mu$. and variance, $\sigma^{2}$, are

$\mu=k / \lambda ; \sigma^{2}=k / \lambda^{2}$

Assuming nominal live load is $1, \mu$ and $\sigma^{2}$ can be expressed in terms of $\lambda_{/ s}$ and $V_{L S s}$ as follows:

$\boldsymbol{\sigma}^{2}=\left(\lambda_{L S} V_{L S}\right)^{2}$.

Then from eqns. 23 and 24, after transformations,

$k=1 / V_{L S S}^{2} ; \lambda=1 /\left(\lambda_{L S} V_{l S}^{2}\right)$

The resulting values of $k$ and $\lambda$ are also given in Table 1.

Transient live load It is assumed that the basic time interval for $L T$ is 7 hours, and that $L T$ occurs once per month. The corre-

\section{TABLE 1}

Parameters of LS-intensity

\begin{tabular}{|c|c|c|c|c|c|}
\hline \multirow{2}{*}{$\begin{array}{l}\text { Structural } \\
\text { Type }\end{array}$} & \multirow{2}{*}{$\begin{array}{l}\text { Tributary area * } \\
\left(\mathrm{m}^{2}\right)\end{array}$} & \multirow{2}{*}{$\begin{array}{l}\text { Mean-to-nominal } \\
\text { ratio } \\
\left(\lambda_{L S}\right)\end{array}$} & \multirow{2}{*}{$\begin{array}{l}\text { Coefficient of } \\
\text { variation } \\
\left(V_{L S}\right)\end{array}$} & \multicolumn{2}{|c|}{ Distribution parameters } \\
\hline & & & & $\vec{k}$ & $\lambda$ \\
\hline \multirow[t]{2}{*}{ Beam } & 20 & 0.24 & 0.70 & 2.04 & 8.50 \\
\hline & 100 & 0.39 & 0.50 & 4.0 & 10.26 \\
\hline \multirow[t]{2}{*}{ Column } & 100 & 0.39 & 0.45 & 4.94 & 12.66 \\
\hline & 1000 & 0.55 & 0.35 & 8.16 & 14.84 \\
\hline
\end{tabular}

* Tributary area is the area over which live load is placed to calculate the load effect. 
TABLE 2

Parameters of $L T$ for 50 years

\begin{tabular}{|c|c|c|c|c|c|}
\hline \multirow{2}{*}{$\begin{array}{l}\text { Structural } \\
\text { Type }\end{array}$} & \multirow{2}{*}{$\begin{array}{l}\text { Tributary area } \\
\left(\mathrm{m}^{2}\right)\end{array}$} & \multirow{2}{*}{$\begin{array}{l}\text { Mean-to-nominal } \\
\text { ratio } \\
\left(\lambda_{T, T}\right)\end{array}$} & \multirow{2}{*}{$\begin{array}{l}\text { Coefficient of } \\
\text { Variation } \\
\left(V_{l .7}\right)\end{array}$} & \multicolumn{2}{|c|}{ Distribution parameters } \\
\hline & & & & $\alpha$ & $u$ \\
\hline \multirow[t]{2}{*}{ Beam } & 20 & 0.60 & 0.19 & 11.5 & 0.0 \\
\hline & 100 & 0.40 & 0.19 & 17.0 & 0.0 \\
\hline \multirow[t]{2}{*}{ Column } & 100 & 0.40 & 0.19 & 17.0 & 0.0 \\
\hline & & 0.20 & 0.19 & 33.0 & 0.0 \\
\hline
\end{tabular}

sponding $n=62571$ (for 50 year lifetime), and $p=0.008$. The CDF of intensity is an extreme type I distribution, with

$F_{I T}(x)=\exp \{-\exp [-\alpha(x / L-u)]\}$

where $L=$ nominal live load, $\alpha, u$ are constants. The corresponding density function $f_{I .7}(x)$ is

$$
\begin{aligned}
f_{L T}(x)= & \frac{\alpha}{L} \exp \left[-\alpha\left(\frac{x}{L}-u\right)\right] \\
& \times \exp \left\{-\exp \left[-\alpha\left(\frac{x}{L}-u\right)\right]\right\}
\end{aligned}
$$

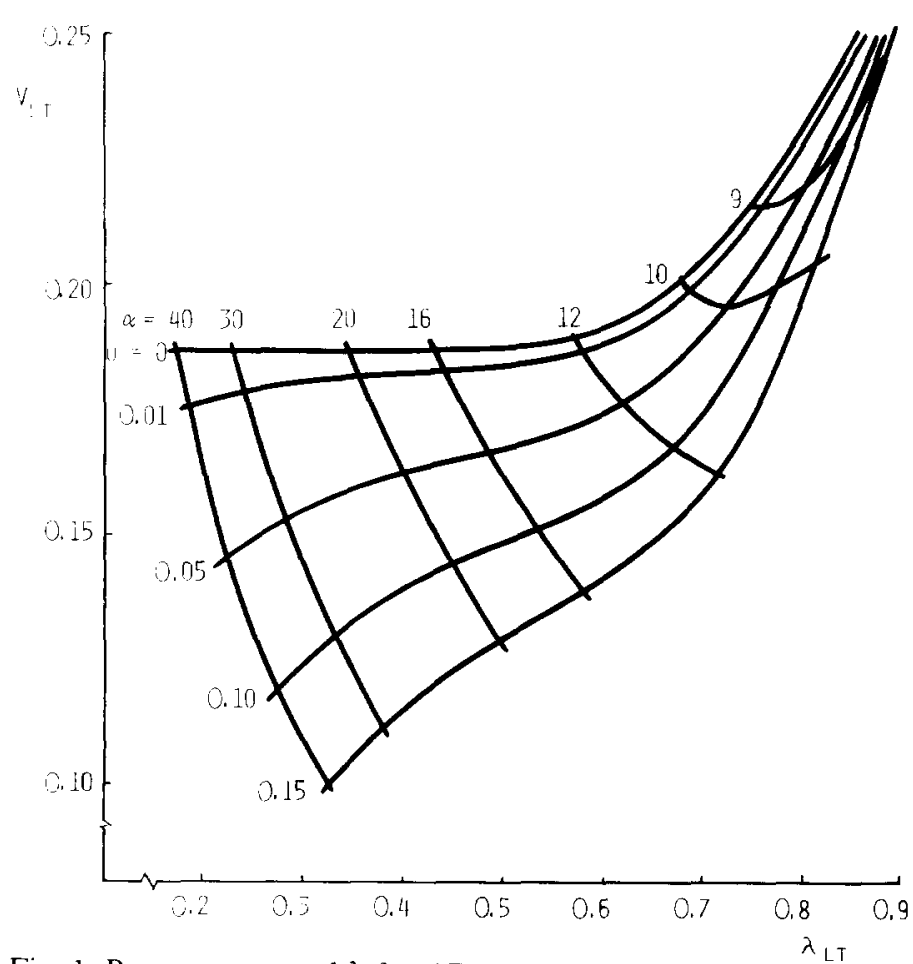

Fig. 1. Parameters $u$ and $\lambda$ for $L T$

The assumed mean-to-nominal ratios and the coefficients of variation for maximum values of $L T$ in 50 years are given in Table 2. The parameters $\alpha$ and $u$ in eqns. 26 and 27 were selected accordingly (see Table 2 ). The relationship between $\alpha, u, \lambda_{L T}$ and $V_{L T}$ is shown in Fig. 1.

Snow The basic period is taken as 8 weeks, and it is assumed that snow occurs once in a year. These assumptions correspond to $n=$ 325 and $p=0.15$. The CDF of intensity is taken as an extreme type I distribution with 
$F_{S}(x)$

$F_{S}(x)=\exp \{-\exp [\alpha(x / S-u)]\}$

where $S=$ nominal snow load, $\alpha$ and $u$ are constants. The probability density function. $f_{S}(x)$, is

$$
\begin{aligned}
f_{S}(x)= & \frac{\alpha}{S} \exp \left[-\alpha\left(\frac{x}{S}-u\right)\right] \\
& \times \exp \left\{-\exp \left[-\alpha\left(\frac{x}{S}-u\right)\right]\right\}
\end{aligned}
$$

The parameters $\alpha$ and $u$ were derived so that the 30 year mean-to-nominal ratio is 0.80 and the coefficient of variation is 0.25 . The corresponding 50 year values are 0.88 and 0.227 respectively. The parameters are $\alpha=6.45, u=$ 0.191 .

Wind It is assumed that wind occurs once in a month and the basic time interval is 4 hours. This corresponds to $n=109,500$ in 50 years and $p=0.005$.

The CDF of intensity is taken as an extreme type I distribution with $F_{W}(x)$ and $f_{W}(x)$ similar to eqns. 28 and 29 , respectively. The parameters $\alpha$ and $u$ were calculated so that 30 year mean-to-nominal and the coefficient of variation were equal to 0.80 and 0.25 respectively (the corresponding 50 year values are 0.875 and 0.177 ). The parameters are $\alpha=$ 7.9, $u=0.0012$.

Earthquake The basic time interval is $\frac{1}{2}$ minute with a once in a year occurrence. This corresponds to $n=52.56 \times 10^{6}$ and $p=$ $0.9513 \times 10^{-6}$.

The CDF of intensity is taken as an extreme type II distribution with

$F_{E}(x)=\exp \left\{-(u E / x)^{k}\right]$

where $E=$ nominal earthquake load, $u$ and $k$ are constants. The constants were calculated from the assumption of 30 year mean-tonominal equal to 0.30 and the coefficient of variation equal to 0.70 . The parameters are $u=0.10$ and $k=4$.

For comparison the 50 year CDF's of all load components are plotted on normal probability paper in Fig. 2 .

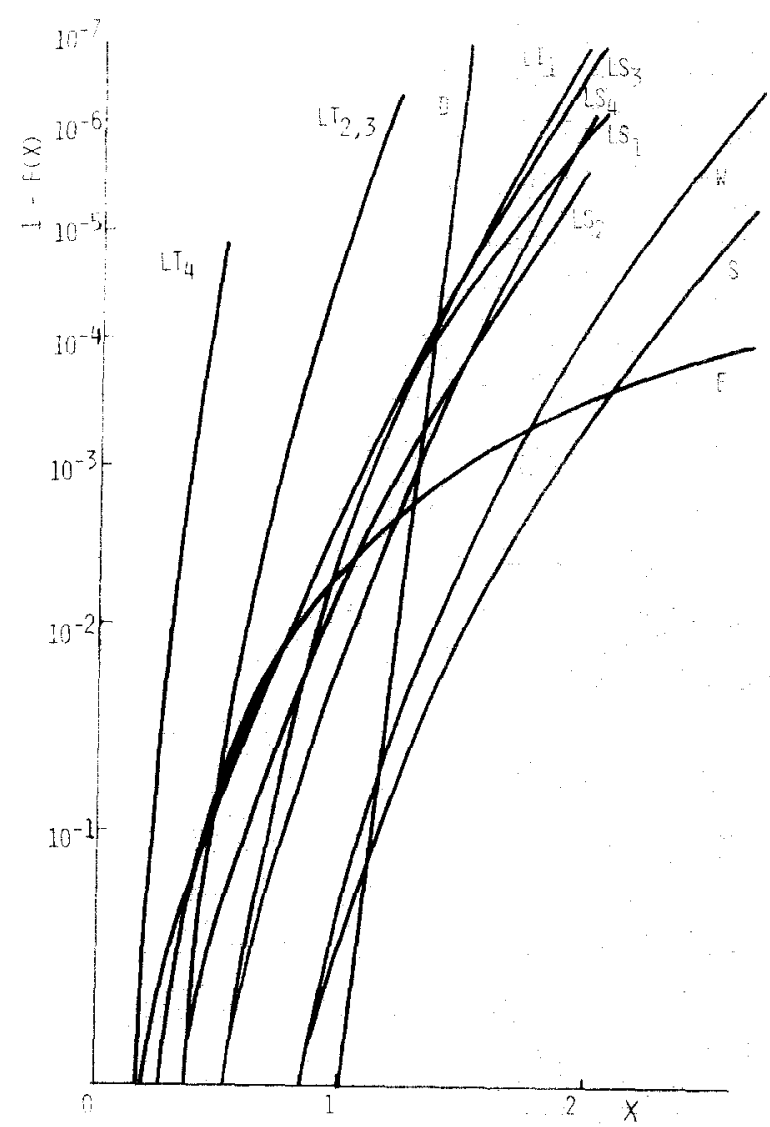

Fig. 2. CDF's for load components ( 50 years), subscripts at $L S$ and $L T: 1$-beams with $A_{\mathrm{t}}=20 \mathrm{~m}^{2}$. 2-beams with $A_{\mathrm{t}}=100 \mathrm{~m}^{2} .3$-columns with $A_{\mathrm{l}}=100 \mathrm{~m}^{2}, 4-\mathrm{col}$ umns with $A_{1}=1000 \mathrm{~m}^{2}$.

\section{DESICN FORMULAS}

Two design options are considered, as provided by the National Builaing Code of Canada [3]. The first one is based on allowable stresses and is refered to as Working Stress Design, WSD. The other one is a load and resistance factor format, refered to as Limit State Design, LSD.

WSD is based on comparison of service loads with allowable loads. The design criterion is,

$$
R / S F \geqslant \max \left\{\begin{array}{l}
D+L \\
D+Q \\
0.75(D+L+Q)
\end{array}\right.
$$


where $D=$ nominal dead load, $L=$ nominal live load, including snow, $Q=$ nominal wind or earthquake, $R=$ nominal resistance, and $S F=$ safety factor.

In the code no distinction is made between $R$ and $S F$, and $R / S F$ is specified as the allowable load. Therefore in this study $R$ in eqn. 31 is replaced with $\bar{R} / \lambda_{R}$, and $S F$ is combined with $\lambda_{R}$ into $\left(\lambda_{R} S F\right)$, so that eqn. 31 becomes

$\bar{R} /\left(\lambda_{R} S F\right)=(\max$. load from eqn. 31$)$

In LSD the design criterion is

$\phi R \geqslant \max \left\{\begin{array}{l}1.25 D+1.5 L \\ 1.25 D+1.5 Q \\ 1.25 D+1.05(L+Q) \\ 0.85 D+1.5 Q\end{array}\right.$

where $D, L, Q$ and $R$ are as in Eq. 31, and $\phi=$ resistance factor.

In the calculations the CDF of resistance is assumed to be lognormal. The parameters of $R$, the ratio of mean to nominal, $\lambda_{R}$, and the coefficient of variation, $V_{R}$, depend on type of material and limit state (flexure, shear, deflection, etc.). Examples of $\lambda_{R}$ and $V_{R}$ for typical

\section{TABLE 3}

Examples of $\lambda_{R}$ and $V_{R}$, from [6]

\begin{tabular}{lll}
\hline $\begin{array}{l}\text { Type of Structure } \\
\text { and Limit State }\end{array}$ & $\begin{array}{l}\text { Mean to } \\
\text { nominal ratio } \\
\left(\lambda_{R}\right)\end{array}$ & $\begin{array}{l}\text { Coefficient } \\
\text { of Variation } \\
\left(V_{R}\right)\end{array}$ \\
\hline $\begin{array}{l}\text { Steel: } \\
\quad \text { girders, flexure }\end{array}$ & 1.08 & 0.12 \\
$\quad$ shear & 1.14 & 0.16 \\
$\quad \begin{array}{l}\text { columns } \\
\text { Reinforced concrete: } \\
\text { beams, flexure } \\
\text { shear } \\
\quad \text { columns }\end{array}$ & 1.08 & 0.14 \\
$\begin{array}{l}\text { Prestressed concrete: } \\
\text { flexure }\end{array}$ & $0.93-1.09$ & $0.17-0.21$ \\
$\begin{array}{l}\text { Timber*: } \\
\text { beams, flexure } \\
\text { shear } \\
\text { columns }\end{array}$ & $1.03-1.06$ & $0.14-0.17$ \\
\hline
\end{tabular}

* Ellingwood [7]. structures are given in Table 3 .

The ratios $\lambda_{R}$ depend on the current nominal values of $R$, and may be subject to change. Therefore in this study the resistance factor, $\phi$, and $\lambda_{R}$ are combined into $\phi / \lambda_{R}$, so that eqn. 33 becomes

$\left(\phi / \lambda_{R}\right) \bar{R}=(\max$. load from eqn. 33$)$

Single resistance factors, $\left(\lambda_{R} S F\right)$ for WSD and $\left(\phi / \lambda_{R}\right)$ for LSD, allow for more flexibility in the interpretation of results.

\section{CALCULATION OF SAFETY INDICES}

Safety indices were computed for beams and columns designed according to the $\mathrm{Na}$ tional Building Code of Canada [3]. The considered combinations include four cases with two loads: $D+L, D+S, D+W$ and $W-D$, and four cases with three loads: $D+L+S$. $D+L+W, D+L+E$, and $D+S+W$, each case with a wide range of load ratios. Four

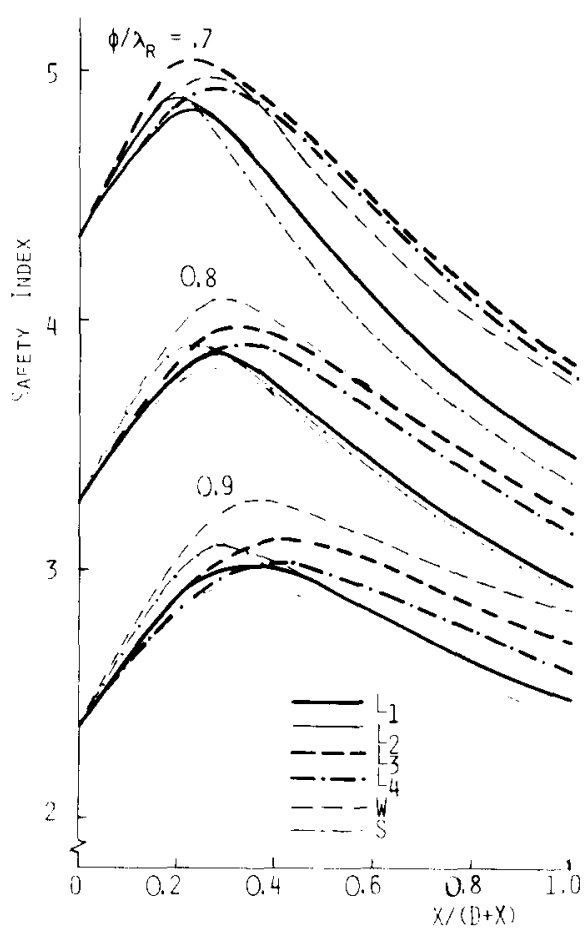

Fig. 3. Safety indices for $\mathrm{LSD}, V_{R}=0.10$. 


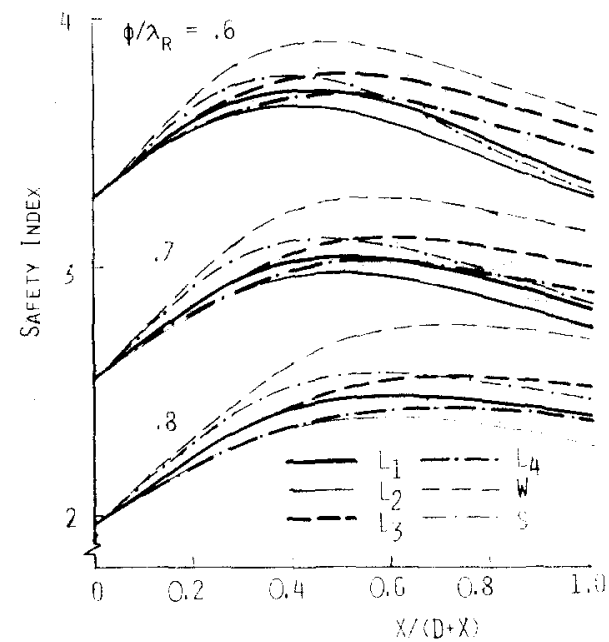

Fig. 4. Safety indices for LSD, $V_{R}=0.20$.

models for live load are considered, according to data in Table 1 and 2.

For each set of loads the mean resistance is calculated using eqn. 32 for WSD and eqn. 34 for LSD. The computations were carried out for WSD for $\left(\lambda_{R} S F\right)$ values ranging from 1.60 to 5.0 , for LSD for $\left(\phi / \lambda_{R}\right)$ from 0.3 to 0.9 ; and for $V_{R}$ equal to 10,20 and $40 \%$.

The results are shown in Figs. $3-8$ and in Tables 4-9. In the figures safety indices are plotted versus the ratio of $X$ to $D+X$, where $X$ is $L, S$ or $W$; in Figs. 3-5 for LSD and

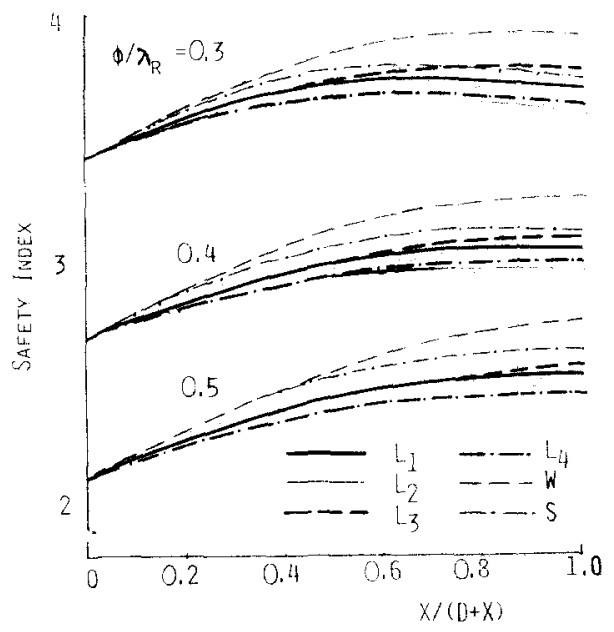

Fig. 5. Safety indices for LSD, $V_{R}=\mathbf{0 . 4 0}$.

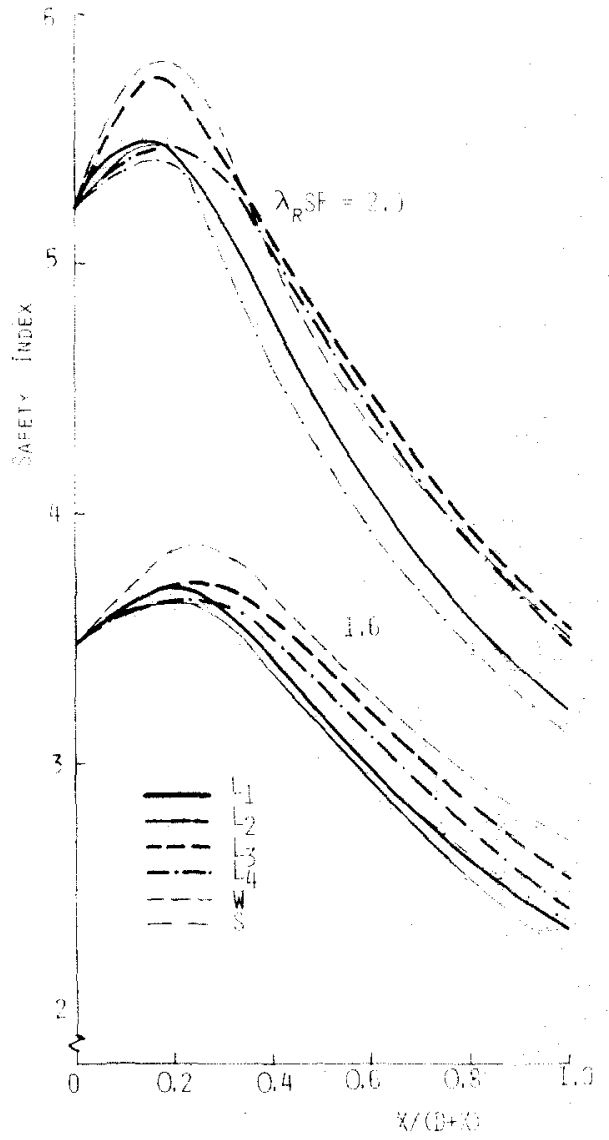

Fig. 6. Safety indices for WSD, $v_{R}=0.10$.

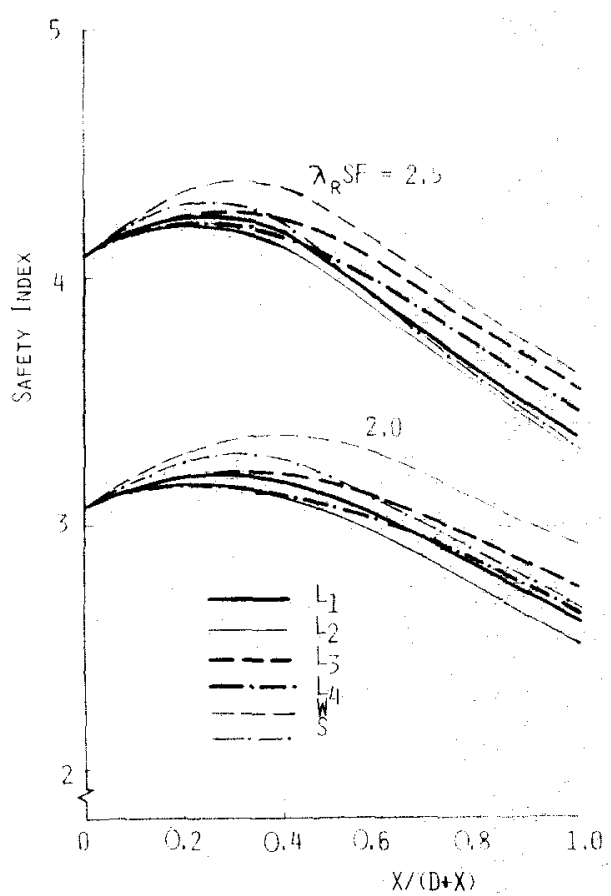

Fig. 7. Safety indices for WSD, $V_{k}=0.20$. 


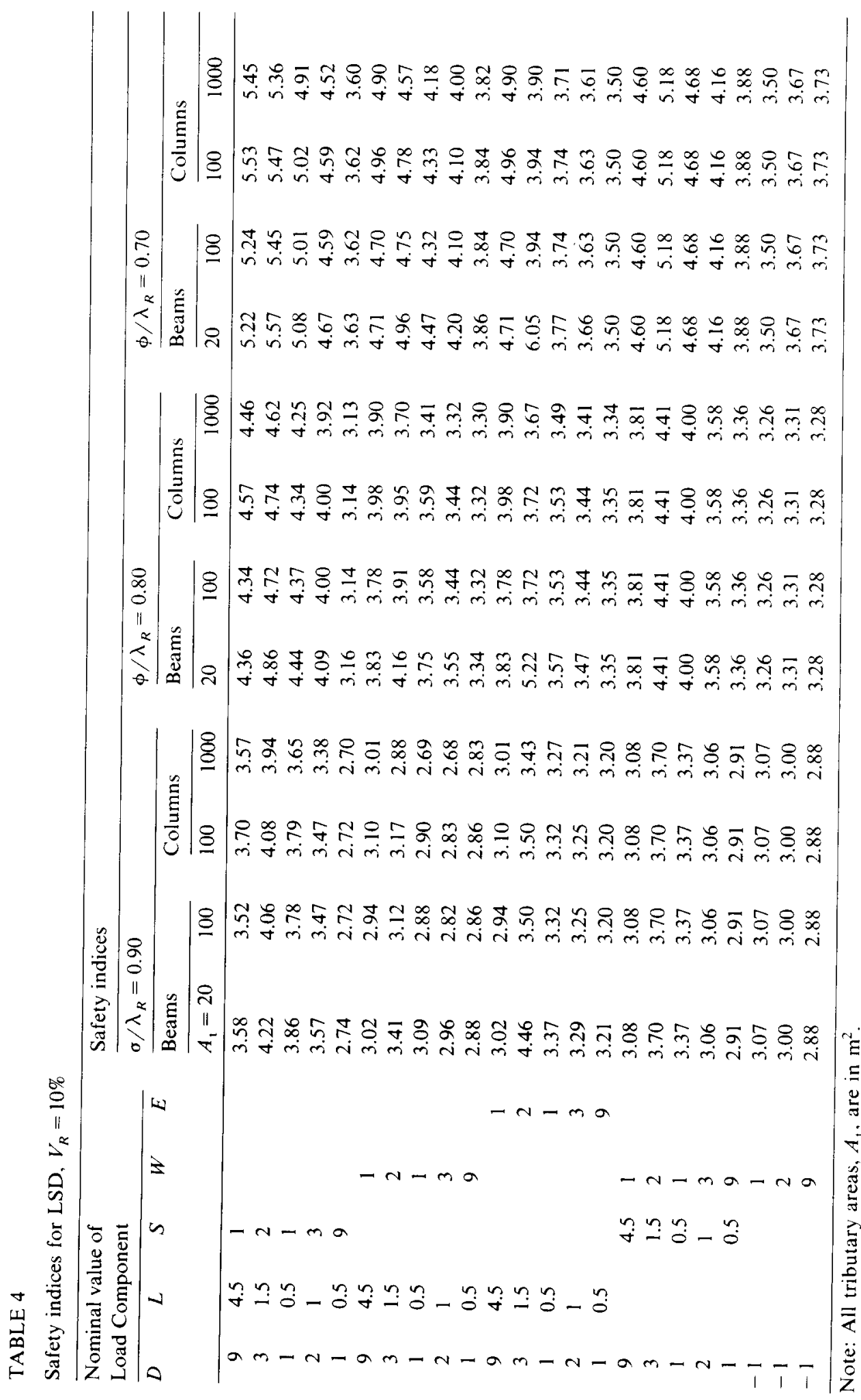




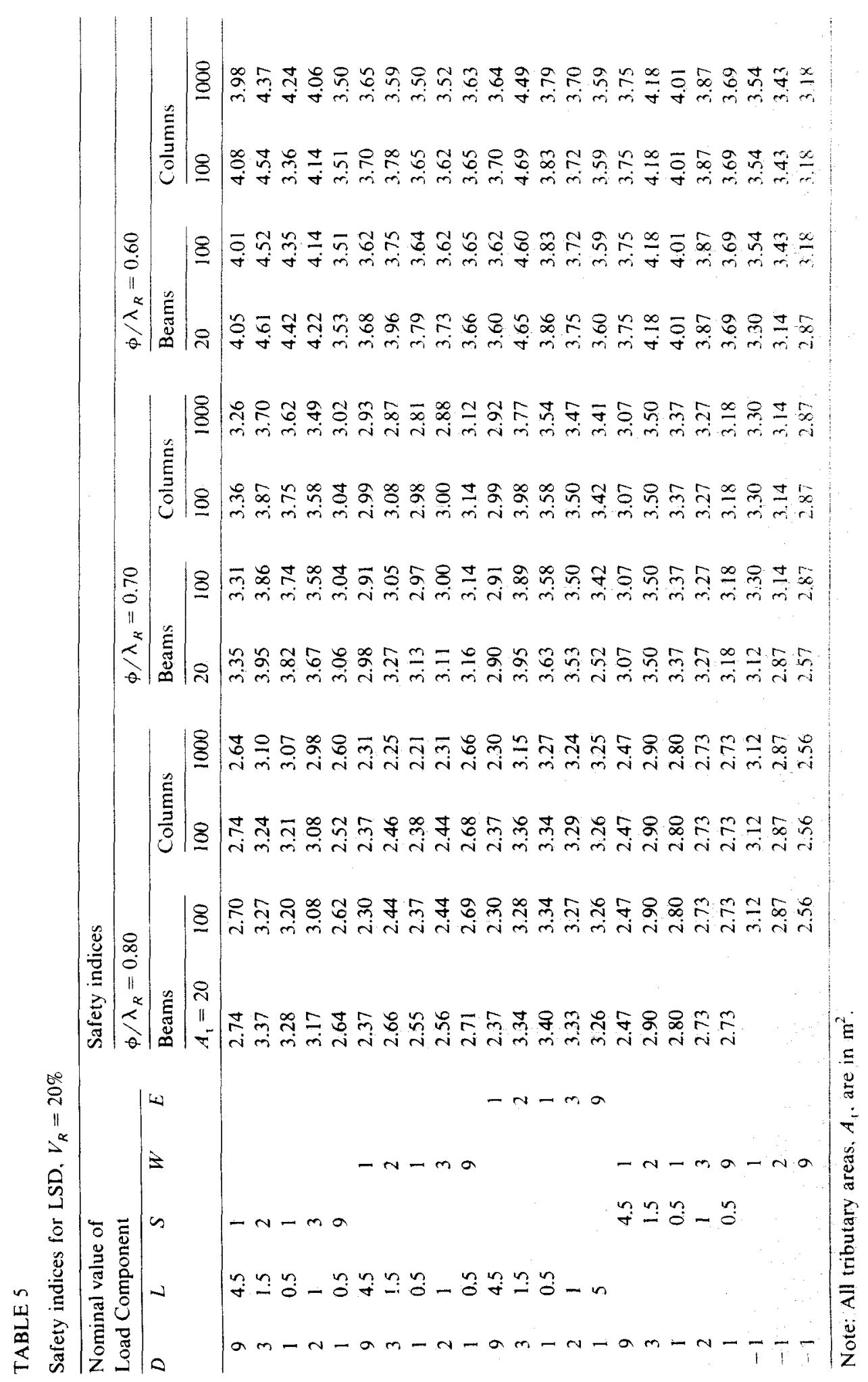




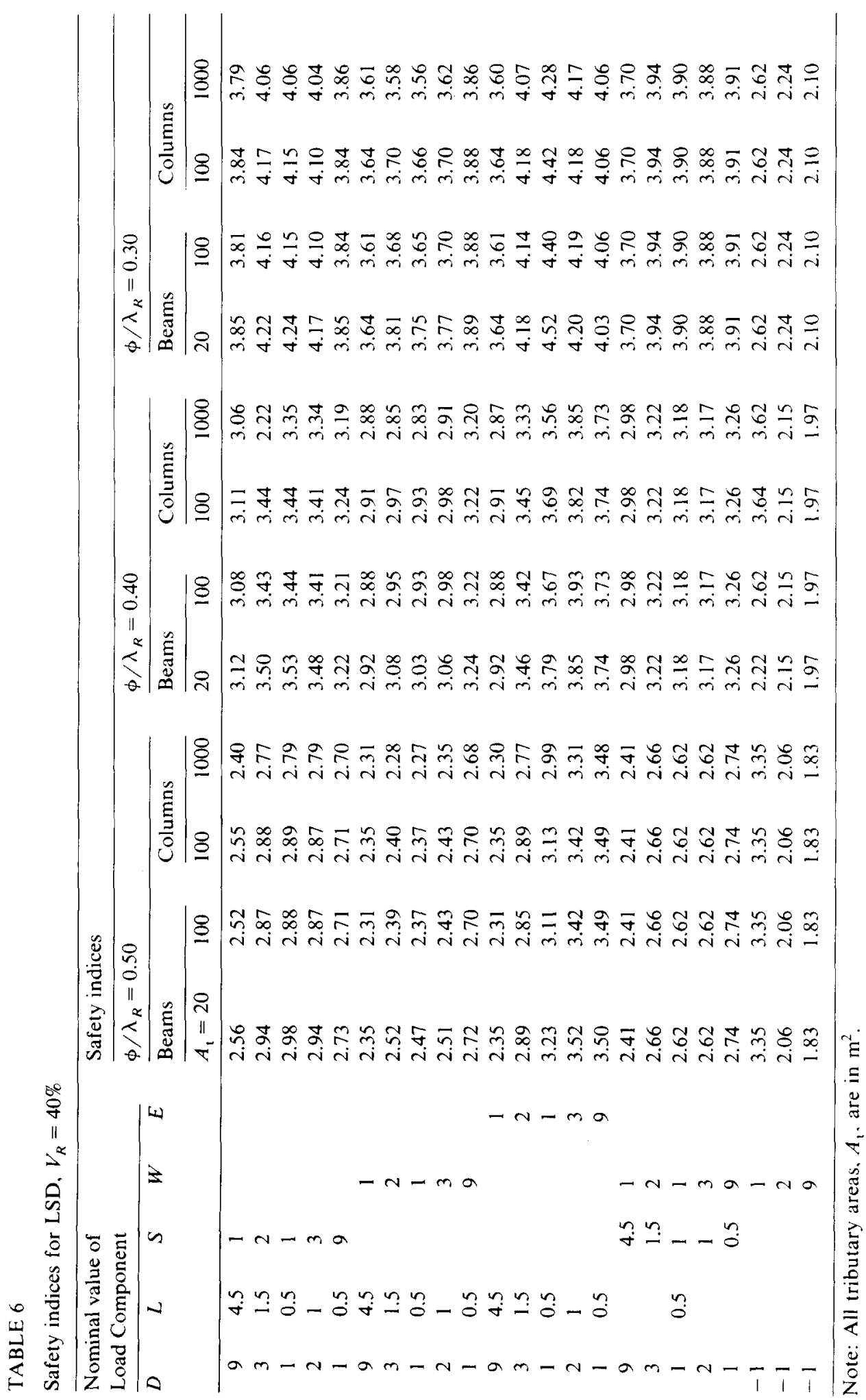




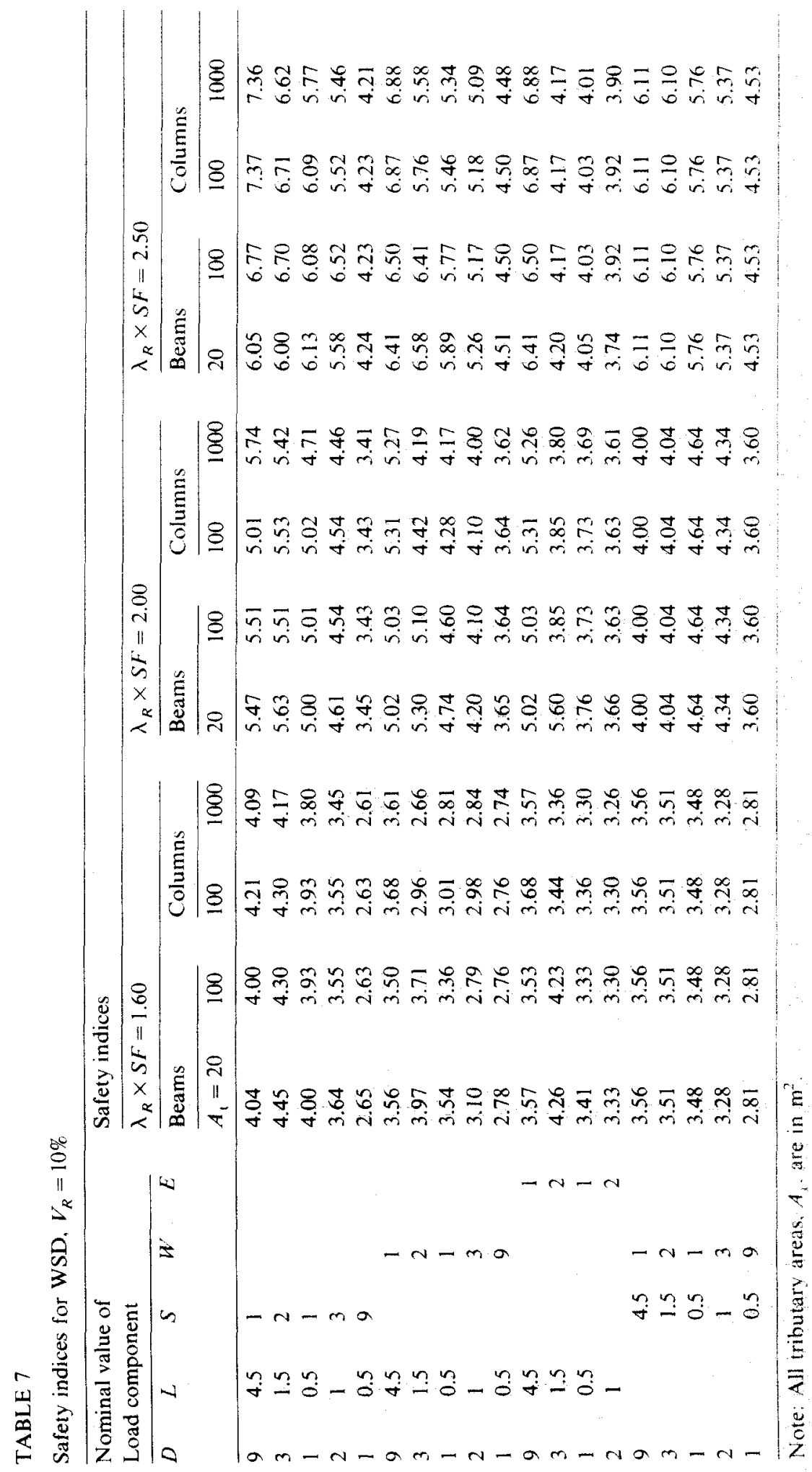




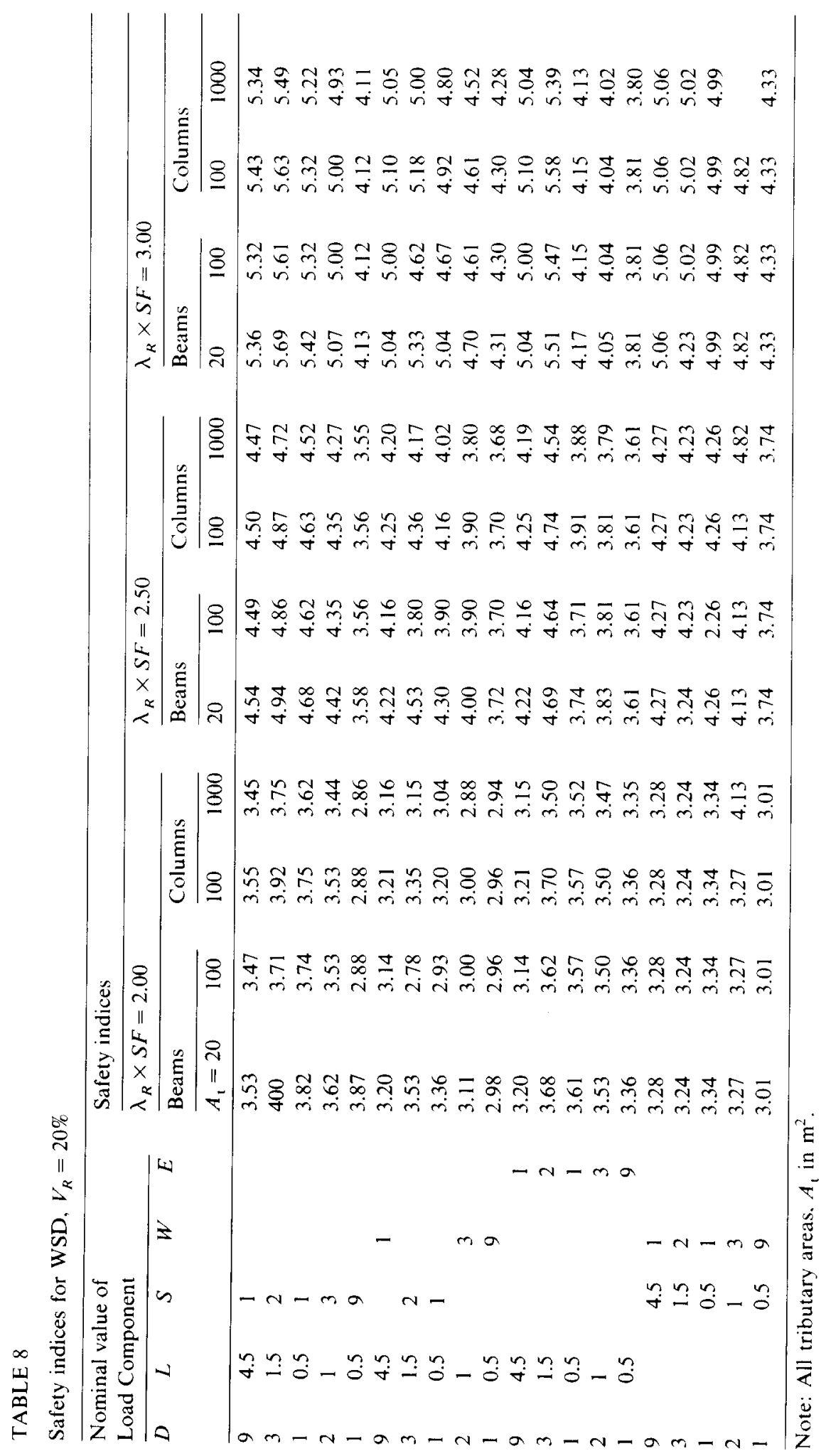




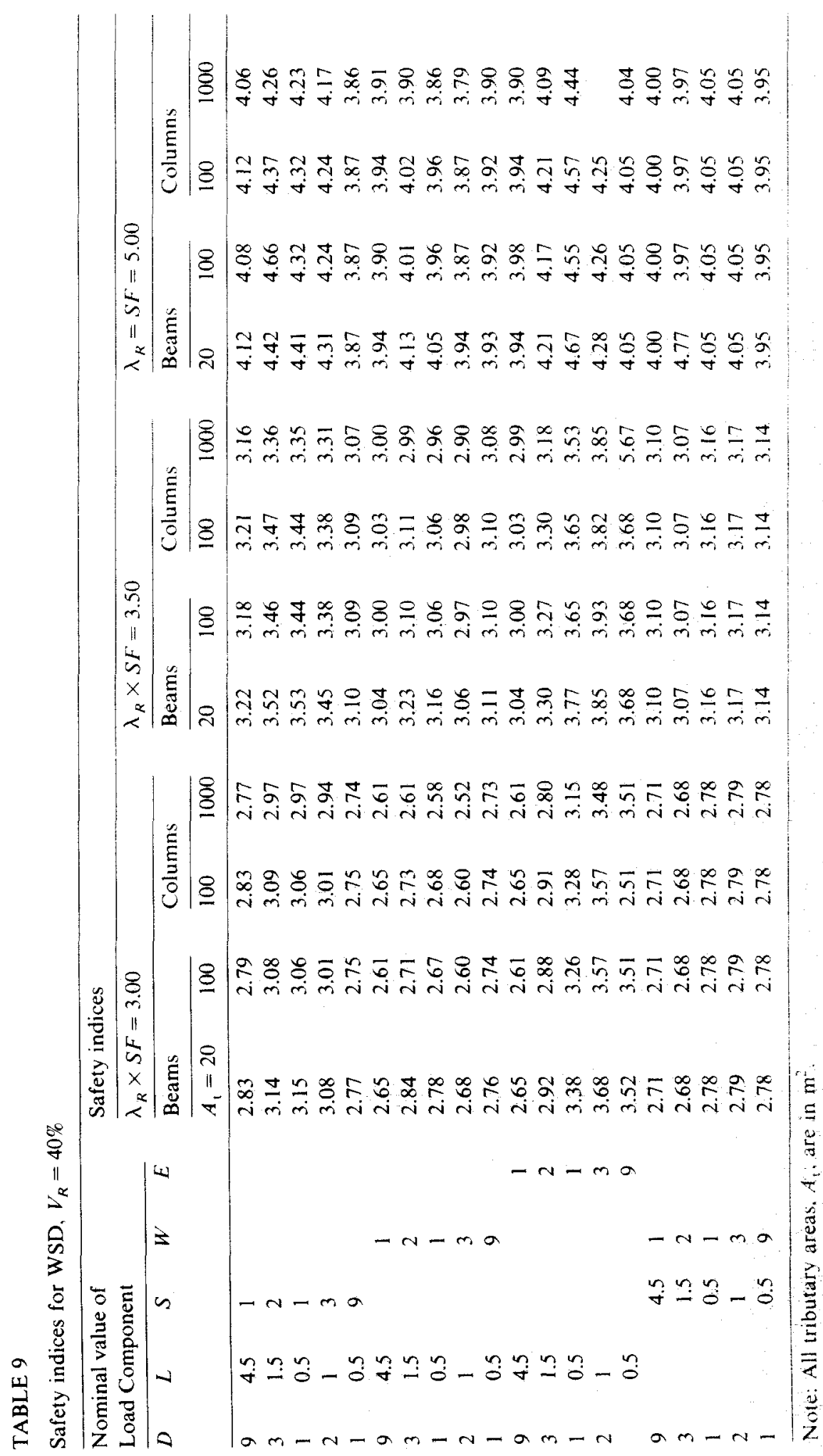




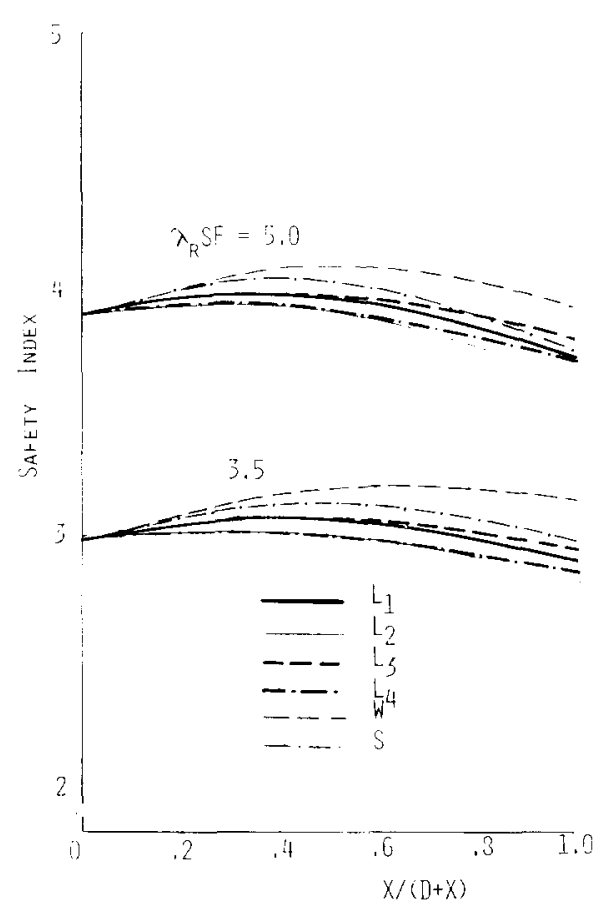

Fig. 8. Safety indices for WSD, $V_{R}=0.40$.

$V R=10-40 \%$, respectively, and in Figs. 6-8 for WSD and $V_{R}=10-40 \%$. The curves in the figures are denoted as follows: $L_{1}$-live load for beams with tributary area $A_{\mathrm{t}}=20 \mathrm{~m}^{2}, L_{2}$ - live load for beams with $A_{\mathrm{t}}=100 \mathrm{~m}^{2}$, $L_{3}$-live load for columns with $A_{\mathrm{t}}=100 \mathrm{~m}^{2}$, $L_{4}$-live load for columns with $A_{\mathrm{t}}=1,000$ $\mathrm{m}^{2}, \mathrm{~S}$ - snow and $\mathrm{W}$-wind. The safety indices computed for the combinations of three loads, and for $W-D$, are presented in the tables; in Tables 4-6 for LSD and $V_{R}=$ $10-40 \%$ and in Tables 7-9 for WSD and $V_{R}=10-40 \%$.

\section{SELECTION OF OPTIMUM f'S AND SFS}

The basic features of a building code are "goodness-of-fit" and simplicity. Since modern codes are developed based on the safety criteria, the goodness-of-fit is also measured in terms of safety. The perfect fit is achieved if safety of all structures designed using the code is at an optimum level. Lind [8] considers the optimum safety as a parameter in the economical analysis (trade-off between cost of design and construction and the expected cost of failure).

The user of the code (designer) is interested in a simple format, and the simplicity depends on the number of different sets of load and resistance factors. However, as in the case of the optimum safety, the optimum simplicity is also a parameter of an economical trade-off. The selection of the optimum safety index and the optimum number of different $\phi$ 's or $S F$ 's is beyond the scope of this paper. However, the calculated safety indices can be used to select the optimum resistance factors and allowable loads for a given target safety index, $\beta_{\mathrm{T}}$.

The basic parameter affecting the selection is the coefficient of variation of resistance, $V_{R}$. For typical structures and materials $V_{R}$ 's are well established, see Table 3.

For a given $V_{R}$, Tables 4-9 and Figs. 3-8 provide a spectrum of $\beta$ 's. The optimum $\left(\phi / \lambda_{R}\right)_{\text {opt }}$ for LSD, or $\left(\lambda_{R} S F\right)_{\text {opt }}$ for WSD, provides the best fit to the preselected $\beta_{\mathrm{T}}$. The selection may also be carried out by assigning weighting factors to various $\beta$ 's in the tables and figures. The weight may represent the importance of the load combination to which it is assigned. Then for each value of $\left(\phi / \lambda_{R}\right)$ in LSD, or $\left(\lambda_{R} S F\right)$ in WSD, the weighted sum of the $\beta$ 's can be calculated. The optimum factor provides the closest fit to $\beta_{\mathrm{T}}$. is

Finally, the optimum resistance factor, $\phi_{\mathrm{opt}}$,

$\phi_{\mathrm{opt}}=\left(\phi / \lambda_{R}\right)_{\mathrm{opt}} \lambda_{R}$

where $\lambda_{R}$ is given in Table 3 for typical structures and materials, and the optimum allowable load is equal to $\left(\lambda_{R} S F\right)_{\mathrm{opt}}$.

\section{CONCLUSIONS}

A procedure has been developed to calculate safety indices for structures designed on 
the basis of given load and resistance factors. The method is based on normal approximations of non-normal distributions at the design point.

Safety indices were calculated for typical cases of load components, including dead load, live load, snow, wind and earthquake. A wide range of resistance parameters (meanto-nominal ratio and coefficient of variation) was considered. The results are presented in tables and in figures.

The calculated values of $\beta$ can be used to select the optimum resistance factors and allowable loads according to the National Building Code of Canada.

\section{ACKNOWLEDGMENTS}

The study was sponsored by the National Research Council of Canada; which is gratefully acknowledged.

The author would like to thank D.E. Allen for his suggestions and comments during the work on the project, and J.D. Curtis and P.
Bosscher for their assistance in computations. Thanks are also due to the anonymous reviewers for their constructive comments.

\section{REFERENCES}

I A.S. Nowak and N.C. Lind. Practical code calibration procedures. Can. J. Civ. Eng. 6 (1979) 112-119.

2 R. Rackwitz and B. Fiessler. Structural reliability under combined random load sequences. Comp. Struct., 9 (1978) 484-494.

3 National Building Code of Canada. National Research Council of Canada, Ottawa, 1977.

4 J.R. Benjamin and C.A. Cornell, Probability, Statistics and Decision for Civil Engineers. McGraw-Hill Book Co., 1970.

5 D.E. Allen, Limit states design a probabilistic study. Can. J. Civ. Eng., 2(1) (1976) 3649.

6 B. Ellingwood, T.V. Galambos. J.G. MacGregor and C.A. Cornell. Development of a Probability Based Load Criterion for American National Standard A $\$ 8$. National Bureau of Standards Special Publications 577. Washington D.C., June 1980

7 B. Ellingwood, Reliability of wood structural elements. Struct. Div. ASCE, 107 (ST 1) (1981) 73-87.

8 N.C. Lind, Approximate analysis and economics of structures. Struct. Div. ASCE, 102 (ST6) (1976) $1177-1196$. 